\title{
Semisynthetic Nanoreactor for Reversible Single-Molecule Covalent Chemistry
}

Joongoo Lee, ${ }^{\dagger}$ Arnold J. Boersma, ${ }^{\dagger}$ Marc A. Boudreau, ${ }^{\S}$ Stephen Cheley, ${ }^{\perp}$ Oliver Daltrop, ${ }^{\dagger}$ Jianwei Li, $^{\dagger}$ Hiroko Tamagaki, ${ }^{\dagger}$ and Hagan Bayley* ${ }^{*} \dagger$

${ }^{\dagger}$ Department of Chemistry, University of Oxford, Oxford OX1 3TA, U.K.

${ }^{\ddagger}$ Groningen Biomolecular Sciences and Biotechnology Institute, University of Groningen, 9747 AG Groningen, The Netherlands

${ }^{\S}$ Department of Chemistry, University of New Hampshire, Durham, New Hampshire 03824, United States

${ }^{\perp}$ Department of Pharmacology, University of Alberta, Edmonton, AB T6G 2R3, Canada

\section{Supporting Information}

ABSTRACT: Protein engineering has been used to remodel pores for applications in biotechnology. For example, the heptameric $\alpha$-hemolysin pore $(\alpha \mathrm{HL})$ has been engineered to form a nanoreactor to study covalent chemistry at the single-molecule level. Previous work has been confined largely to the chemistry of cysteine side chains or, in one instance, to an irreversible reaction of an unnatural amino acid side chain bearing a terminal alkyne. Here, we present four different $\alpha \mathrm{HL}$ pores obtained by coupling either two or three fragments by native chemical ligation (NCL). The synthetic $\alpha \mathrm{HL}$ monomers were folded and incorporated into heptameric pores. The functionality of the pores was validated by hemolysis assays and by single-channel current recording. By using NCL to introduce a ketone amino acid, the nanoreactor approach was extended to an investigation of reversible covalent chemistry on an unnatural side chain at the single-molecule level.

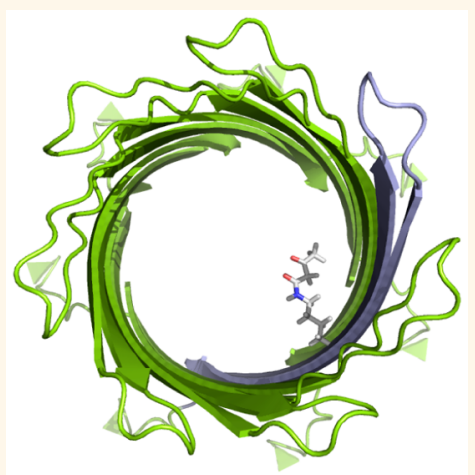

KEYWORDS: nanoreactor, single-molecule chemistry, membrane protein, native chemical ligation, unnatural amino acid, protein semisynthesis

$\alpha$-Hemolysin $(\alpha \mathrm{HL})$ is a pore-forming toxin secreted by Staphylococcus aureus. The pore contains seven subunits, and each subunit comprises 293 amino acids. ${ }^{1}$ Use of the heptameric $\alpha \mathrm{HL}$ protein pore as a nanoreactor has proved profitable in studies of covalent chemistry at the singlemolecule level. $^{2-5}$ For example, the nanoreactor approach is advantageous because large, potentially interfering, fluorescent probes are not required. When a molecule undergoes a chemical reaction on the inner wall of the transmembrane $\beta$ barrel of the $\alpha \mathrm{HL}$ pore, the current carried by ions flowing through the pore is perturbed. Hence, individual reaction steps, including those that are not rate-limiting and therefore not detectable at the ensemble level, are visualized in the microsecond time domain, and the kinetics of each step can be determined. ${ }^{2-5}$ Recently, complex reaction networks ${ }^{4}$ and the motion of individual molecular walkers ${ }^{5}$ have been examined by this means. However, the chemistry carried out within engineered $\alpha \mathrm{HL}$ nanoreactors has until recently been confined to the reactions of thiolates ${ }^{2-8}$ and derivatives of the side chains of cysteine residues. ${ }^{9,10}$ Lately, we expanded the range of chemistry that can be approached by introducing unnatural amino acid side chains into the $\alpha \mathrm{HL}$ polypeptide by using native chemical ligation (NCL). ${ }^{11}$ By this means, an irreversible reaction of a side chain bearing a terminal alkyne was examined. In the present work, we advance the unnatural amino acid approach by introducing a ketone side chain which allows for observation of reversible chemistry. We also describe truncated pores made by the NCL approach.

\section{RESULTS}

General Approach to Two-Fragment Ligation. Twofragment ligations involved the reaction of an $\mathrm{N}$-terminal fragment (NTF) containing a C-terminal ${ }^{\alpha}$ thioester with a Cterminal fragment (CTF) bearing an $\mathrm{N}$-terminal cysteine (NCys). The NTF coding sequence was fused in-frame with DNA encoding a Mycobacterium xenopi DNA gyrase A (Mxe GyrA) intein-chitin binding domain (CBD), that is, NTF-intein$\mathrm{CBD}$, in the pTXB3 plasmid (New England Biolabs). ${ }^{12}$ After expression of the protein in Escherichia coli, the NTF- ${ }^{\alpha}$ thioester was cleaved from the intein-CBD with sodium 2-mercaptoethanesulfonate (MESNa), while the rest of the chimera remained bound to chitin beads. ${ }^{13,14}$ A CTF with an N-Cys can be generated by cleavage of a precursor fusion protein with a site-specific protease. ${ }^{15,16}$ However, this method may not work

\footnotetext{
Received: July 13, 2016

Accepted: August 18, 2016

Published: August 18, 2016
} 
A
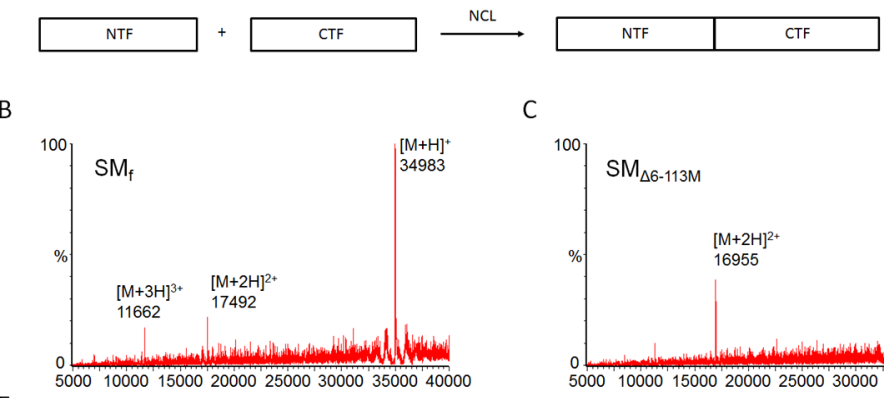

$\stackrel{\text { fold and assemble }}{\longrightarrow}$

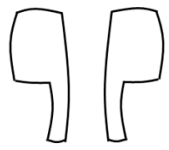

C

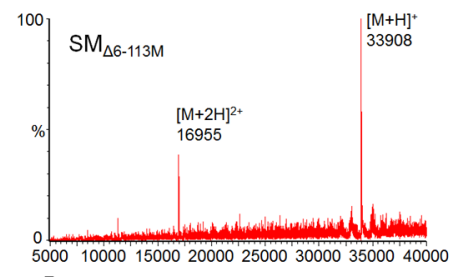

$\mathrm{F}$

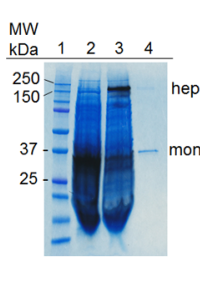

G

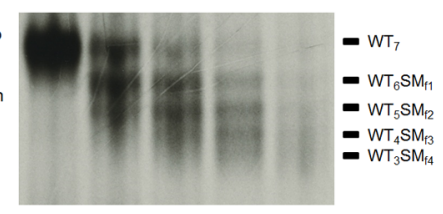

D

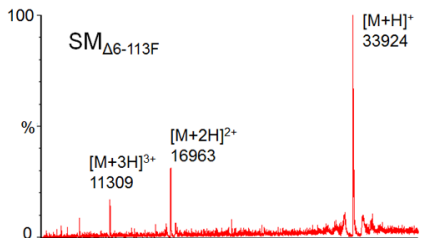

500010000150002000025000300003500040000 mass $(\mathrm{m} / \mathrm{z})$

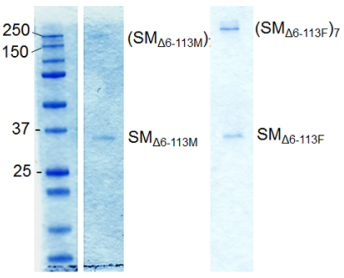

Figure 1. Preparation of $\alpha \mathrm{HL}$ pores. (A) $\alpha \mathrm{HL}$ monomers were synthesized by native chemical ligation from two fragments (NTF and CTF) expressed in E. coli. Folding was performed by reducing the concentration of the denaturant $(8 \mathrm{M}$ urea $)$ present during the purification of the synthetic monomers (SM). (B-D) Characterization of the synthetic $\alpha$ HL monomers by LC-MS. (B) SM f $^{:}\left[M+H^{+}=34983\right.$ (observed mass, obs), 34981 (calculated mass, calcd). (C) SM S6-113M: $[\mathrm{M}+\mathrm{H}]^{+}=33908$ (obs), 33907 (calcd). (D) SM $\mathrm{SM}_{\Delta 6-113 \mathrm{~F}}:[\mathrm{M}+\mathrm{H}]^{+}=33924$ (obs), 33923 (calcd). (E) Hemolysis assays (see Supporting Information, Experimental procedures). The decrease in light scattering over time was recorded in a microplate reader at $595 \mathrm{~nm}$. WT $\alpha \mathrm{HL}$ monomer (row 1) lysed rRBCs, whereas TBM $\Delta 6$ (row 3 ) did not due to its truncated $\beta$ barrel. Similarly, the full-length synthetic $\alpha \mathrm{HL}$ monomer $\mathrm{SM}_{\mathrm{f}}\left(5.9 \mu \mathrm{g} \mathrm{mL}^{-1}\right.$, in well 1) lysed rRBCs, whereas $\mathrm{SM}_{\Delta 6-113 \mathrm{M}}\left(7.4 \mu \mathrm{g} \mathrm{mL}{ }^{-1}\right)$ and $S_{\Delta 6-113 \mathrm{~F}}\left(7.8 \mu \mathrm{g} \mathrm{mL}^{-1}\right)$ did not. WT and TBM $\Delta 6$ monomers were produced by IVTT. (F) SDS-PAGE gel analysis of WT and synthetic $\alpha H L$ $\left(\mathrm{SM}_{\mathrm{f}}\right)$. Lane 1: molecular markers. Lane 2: radiolabeled $\alpha \mathrm{HL}$ monomer (mon) produced by IVTT. Lane 3: radiolabeled WT $\mathrm{W}_{7} \mathrm{pres}(\mathrm{hep})$ produced in the presence of DPhPC liposomes $\left(7 \mathrm{mg} \mathrm{mL}^{-1}\right)$. Lane 4: $\left(\mathrm{SM}_{\mathrm{f}}\right)_{7}$ pores assembled with purified $\mathrm{SM}_{\mathrm{f}}$ in the presence of $\mathrm{DPhPC}$ liposomes under the same conditions comigrate with the $\mathrm{WT}_{7}$ pore. An autoradiogram is superimposed on the Coomassie Blue-stained gel. (G) Heteroheptameric pores. WT $\alpha \mathrm{HL}$ (radiolabeled protein) and SM were mixed in various ratios in the presence of rRBCm to yield heteromeric $\mathrm{WT}_{7-n} \mathrm{SM}_{n}(n=0-7)$ pores. The heptameric pores with different numbers of $\mathrm{SM}_{\mathrm{f}}$ were separated by SDS-PAGE based on the different electrophoretic mobilities produced by $\mathrm{D}_{8}$ tails at the C-terminus of $\mathrm{SM}_{\mathrm{f}} \cdot(\mathrm{H})$ Homoheptameric pores formed with $\mathrm{SM}_{\Delta 6-113 \mathrm{M}}(\mathrm{left})$ and $S_{\Delta 6-113 F}\left(\right.$ right). Homomeric pores were prepared in the presence of DPhPC liposomes $\left(10 \mathrm{mg} \mathrm{mL}^{-1}\right)$.

efficiently with proteins of poor solubility or proteins from inclusion bodies. In the latter case, the protease can be inactivated by denaturants used to solubilize a target protein, and even if cleavage is successful, an additional purification step may be required to separate the product from the protease and unwanted fragments. An alternative approach to generate $\mathrm{N}$ Cys, which was taken here, is to express the polypeptide initiated by fMet-Cys. Following expression, formylmethionine (fMet) is removed by endogenous deformylation and methionine aminopeptidase activity, and the $\mathrm{N}$-Cys residue undergoes condensation with pyruvic acid, an abundant metabolite, to form a thiazolidine. ${ }^{17}$ This strategy is proteasefree and allows rapid overexpression of the target polypeptide $(4 \mathrm{~h})$ at $37{ }^{\circ} \mathrm{C}$. The polypeptide accumulated in inclusion bodies is subsequently purified under denaturing conditions $(8$ $\mathrm{M}$ urea or $6 \mathrm{M}$ guanidine hydrochloride $(\mathrm{Gu} \cdot \mathrm{HCl}))$, and the $\mathrm{N}$ Cys is unmasked with hydroxylamine or a hydroxylamine derivative. ${ }^{18}$ The use of denaturants enables the purification of polypeptides containing transmembrane regions, which are often insoluble and obtained in very low yields when processed under nondenaturing conditions (unpublished work).

Preparation of Polypeptides for Two-Fragment Ligation. We targeted three $\alpha \mathrm{HL}$ polypeptides for semisynthesis by two-fragment coupling (Figure 1A): a full-length $\alpha \mathrm{HL}$ monomer and two different truncated barrel mutants (TBM $\Delta 6$ ) (Figure S1A-C). TBM $\Delta 6$ forms an $\alpha \mathrm{HL}$ heptamer in which amino acids have been removed in pairwise fashion from both of the two $\beta$ strands contributed by each subunit, resulting in a $\beta$ barrel shortened by 6 amino acids. ${ }^{19}$ TBM $\Delta 6$ forms conductive pores despite the short length of the barrel, presumably by inducing the formation of toroidal lipid pores that span the bilayer. ${ }^{19}$ Two TBM $\Delta 6$ s bearing a different amino acid at residue 113 (Met, Phe) were chosen, as it has been shown that the mutation Met-113 $\rightarrow$ Phe significantly alters the binding kinetics of cyclodextrin adaptors to the pore. ${ }^{20}$

Three different NTFs $\left(\mathrm{NTF}_{126}\left[\mathrm{Ala}^{1}-\mathrm{Gly}^{126}\right], \mathrm{NTF}_{113 \mathrm{M}}\left[\mathrm{Ala}^{1}\right.\right.$ $\left.\mathrm{Met}^{113}\right]$, and $\left.\mathrm{NTF}_{113 \mathrm{~F}}\left[\mathrm{Ala}^{1}-\mathrm{Phe}^{113}\right]\right)$ each bearing an ${ }^{\alpha}$ thioester at the C-terminus were obtained by thiolysis of the corresponding intein-CBD fusion proteins after expression in E. coli. The pTXB3- $\mathrm{NTF}_{126}$ and $\mathrm{pTXB3}-\mathrm{NTF}_{113 \mathrm{M}}$ plasmids were prepared by cloning PCR-amplified DNA, encoding residues $1-126$ and $1-113$ of $\alpha \mathrm{HL}$, upstream of the inteinCBD codons (Figure S2A,B). pTXB3- $\mathrm{NTF}_{113 \mathrm{~F}}$ was prepared by mutagenesis of $\mathrm{pTXB} 3-\mathrm{NTF}_{113 \mathrm{M}}$ by homologous recombination (Figure S2C). ${ }^{21}$ Fusion proteins were produced in E. coli (BL21(DE3), NEB) and solubilized from inclusion bodies under denaturing conditions ( $8 \mathrm{M}$ urea). The NTF- ${ }^{\alpha}$ thioesters were obtained by on-column thiolysis of the fusion proteins bound to chitin columns with MESNa (Figure S3). The purified NTF- ${ }^{\alpha}$ thioesters were characterized by LC-MS (Figure S4, $\mathrm{NTF}_{126}:[\mathrm{M}+\mathrm{H}]^{+}=14150$ (obs), $14150 \mathrm{Da}$ (calcd); $\mathrm{NTF}_{113 \mathrm{M}}:[\mathrm{M}+\mathrm{H}]^{+}=12838$ (obs), $12838 \mathrm{Da}$ (calcd); $\mathrm{NTF}_{113 \mathrm{~F}}:[\mathrm{M}+\mathrm{H}]^{+}=12853$ (obs), $12854 \mathrm{Da}$ (calcd)).

The pT7-SC1-CTF 127 plasmid was prepared by replacing plasmid DNA encoding residues 1-127 with the codons for Met-Cys as previously reported. ${ }^{11}$ To produce $\mathrm{CTF}_{\Delta 114}$, pT7- 

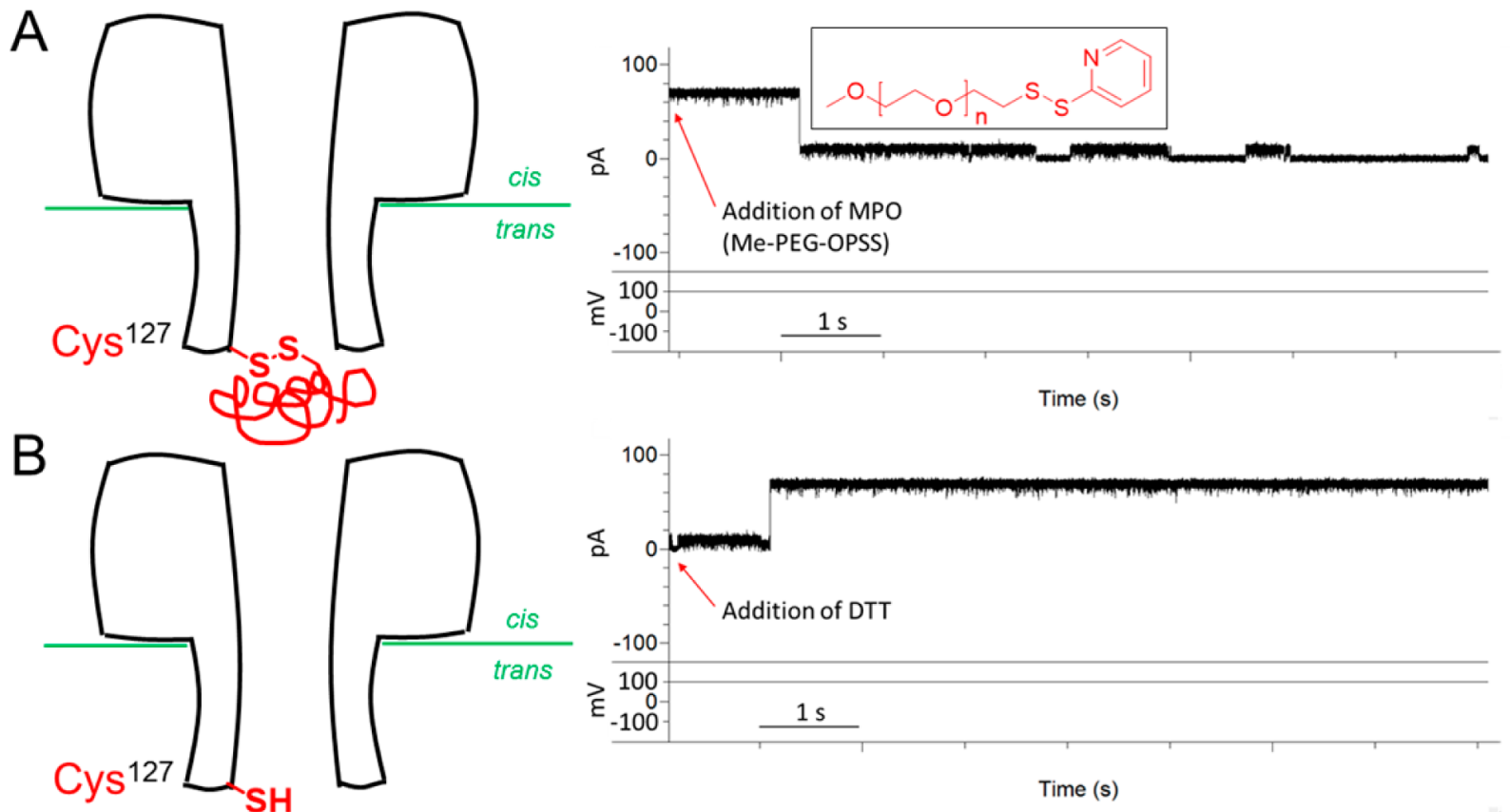

Figure 2. Reactivity of the Cys-127 residue in $\mathrm{WT}_{6} \mathrm{SM}_{\mathrm{f} 1} \alpha \mathrm{HL}$. (A) $\mathrm{WT}_{6} \mathrm{SM}_{\mathrm{f} 1}$ was eluted from a gel (Figure 1G), and a single $\mathrm{WT}_{6} \mathrm{SM}_{\mathrm{f1}}$ pore was established in a planar bilayer. Me-PEG-OPSS $(5 \mathrm{kDa}, 0.1 \mathrm{mM}$, inset, $n=3)$ was added to the trans compartment. The current drop indicates a blockade caused by reaction of the PEG derivative with the pore through the formation of a disulfide bond with the side chain of Cys-127. (B) Addition of $5 \mathrm{mM}$ DTT to both compartments cleaved the PEG chain from the $\mathrm{WT}_{6} \mathrm{SM}_{\mathrm{fl}}$ pore. The buffer was $1 \mathrm{M} \mathrm{KCl,} 20 \mathrm{mM} \mathrm{Tris} \cdot \mathrm{HCl}$ (pH 8.5). The currents in (A) and (B) were filtered and sampled at 2 and $10 \mathrm{kHz}$, respectively.

SC1-CTF $\mathrm{CT114}_{-\mathrm{DH}}$ was prepared by two successive homologous recombinations ${ }^{21}$ from $\mathrm{pT} 7-\mathrm{TBM} \Delta 6$, which encodes TBM $\Delta 6$ (Figure S5). The codons for residues 1-113 were removed (retaining the initiator Met), and codons for a $\mathrm{D}_{8} \mathrm{H}_{6}(\mathrm{DH})$ tag were added in the first and second rounds, respectively. The two different C-terminal fragments $\left(\mathrm{CTF}_{127}\left[\mathrm{Cys}^{127}-\mathrm{Asn}^{293}\right]\right.$ $\mathrm{D}_{8} \mathrm{H}_{6}$, and $\mathrm{CTF}_{\Delta 114}\left[\mathrm{Cys}^{114}-\mathrm{Asn}^{293}, \Delta \mathrm{Phe}^{120}-\mathrm{Thr}^{125}, \Delta\right.$ Gly $^{133}$ $\left.\mathrm{Ala}^{138}\right]-\mathrm{D}_{8} \mathrm{H}_{6}$ ) were overexpressed in E. coli. Like the NTFs, the CTFs were obtained from inclusion bodies and, in this case, purified under denaturing conditions $(6 \mathrm{M} \mathrm{Gu} \cdot \mathrm{HCl})$ by FPLC ( $\ddot{A} K T A$ purifier, GE Healthcare Life Sciences) at room temperature by use of the $\mathrm{His}_{6}$ tag at the C-terminus (Figure S6). The N-terminal fMet was found to be absent, and the thiazolidine produced by condensation of the $\mathrm{N}$-Cys with pyruvic acid was removed with $0.4 \mathrm{M} \mathrm{HONH}_{2} \cdot \mathrm{HCl}$ for $4 \mathrm{~h}$ at room temperature. The purified CTFs were characterized by LC-MS (Figure S7, $\mathrm{CTF}_{127}:[\mathrm{M}+\mathrm{H}]^{+}=20974$ (obs), 20974 $\mathrm{Da}$ (calcd); $\mathrm{CTF}_{\Delta 114}:[\mathrm{M}+\mathrm{H}]^{+}=21214$ (obs), $21212 \mathrm{Da}$ (calcd)).

$\alpha$-Hemolysin Polypeptides by Two-Fragment Ligation. We ligated NTFs and CTFs (Figure S1) in NCL buffer [200 mM NaH${ }_{2} \mathrm{PO}_{4}(\mathrm{pH} 6.9), 6 \mathrm{M} \mathrm{Gu} \cdot \mathrm{HCl}, 200 \mathrm{mM}$ 4mercaptophenylacetic acid (MPAA), and $50 \mathrm{mM}$ tris(2carboxyethyl)phosphine (TCEP)] to make three different $\alpha \mathrm{HL}$ constructs. In each case, an NTF and a CTF were mixed and the buffer was exchanged by dilution-concentration cycles with a centrifugal filter. $\mathrm{NTF}_{126}(\sim 0.5 \mathrm{mM})$ and $\mathrm{CTF}_{127}$ $(\sim 0.5 \mathrm{mM})$ were coupled to produce the full-length $\alpha \mathrm{HL}$ synthetic monomer $\left(\mathrm{SM}_{\mathrm{f}}\right) . \mathrm{NTF}_{113 \mathrm{M}}(\sim 0.6 \mathrm{mM})$ and $\mathrm{NTF}_{113 \mathrm{~F}}$ $(\sim 0.7 \mathrm{mM})$ were separately coupled with $\mathrm{CTF}_{\Delta 114}(\sim 0.8 \mathrm{mM})$ to yield two different truncated mutant monomers ${ }^{19}$ $\left(\mathrm{SM}_{\Delta 6-113 \mathrm{M}}\right.$ and $\left.\mathrm{SM}_{\Delta 6-113 \mathrm{~F}}\right)$. The rate of ligation is highly dependent on the steric properties of the C-terminal amino acid residue of an $\mathrm{NTF}^{22,23}$ and the concentration of reactants.
The ligation reactions were carried out for $>12 \mathrm{~h}$ at a final concentration of $\sim 1 \mathrm{mM}$ as previous work ${ }^{22}$ had suggested that ligations of NTFs containing C-terminal Ala, Val, Ile, Met, and Phe are completed within $9 \mathrm{~h}$ at a final peptide concentration of 1-3 mM. The two-fragment couplings gave $\mathrm{SM}_{\mathrm{f}}, \mathrm{SM}_{\Delta 6-113 \mathrm{M}}$, and $\mathrm{SM}_{\Delta 6-113 \mathrm{~F}}$ (Figures $S 8$ and $S 9$ ) in 48, 46, and $50 \%$ yields, respectively.

Purification, Folding, and Functional Properties of $\alpha$ Hemolysin Polypeptides. We purified the $\mathrm{SMs}\left(\mathrm{SM}_{\mathrm{f}}\right.$, $\mathrm{SM}_{\Delta 6-113 \mathrm{M}}$, and $\left.\mathrm{SM}_{\Delta 6-113 \mathrm{~F}}\right)$ by gel filtration in $8 \mathrm{M}$ urea (Figure S8) and characterized them by LC-MS (Figure 1B-D and Figure S8, $\mathrm{SM}_{\mathrm{f}}:[\mathrm{M}+\mathrm{H}]^{+}=34983$ (obs), $34981 \mathrm{Da}$ (calcd); $\mathrm{SM}_{\Delta 6-113 \mathrm{M}}:[\mathrm{M}+\mathrm{H}]^{+}=33908$ (obs), $33907 \mathrm{Da}$ (calcd); $\mathrm{SM}_{\Delta 6-113 \mathrm{M}}:[\mathrm{M}+\mathrm{H}]^{+}=33924$ (obs), $33923 \mathrm{Da}$ (calcd)). We then folded the purified SMs by diluting the $8 \mathrm{M}$ urea in the purification buffer to $\sim 60 \mathrm{mM}$ and concentrating the proteins using a centrifugal filter (MWCO $3 \mathrm{k}$ ). The folded monomers were examined for hemolytic activity toward rabbit red blood cells (rRBCs) (Figure 1E). We observed similarities between the synthetic monomers and the WT or truncated $\alpha \mathrm{HL}$ monomers produced either in $E$. coli or by in vitro transcription and translation (IVTT). As expected, only $\mathrm{SM}_{\mathrm{f}}$ exhibited hemolytic activity toward rRBCs. ${ }^{19}$ The specific hemolytic activity of $\mathrm{SM}_{\mathrm{f}}$ was $\mathrm{HC}_{50}=92 \mathrm{ng} \mathrm{mL} \mathrm{L}^{-1}$, which is in the same range as that of WT $\alpha \mathrm{HL}\left(\mathrm{HC}_{50}=31 \mathrm{ng} \mathrm{mL}^{-1}\right){ }^{24} \mathrm{To}$ visualize the formation of $\alpha \mathrm{HL}$ heptamers, we incubated $\mathrm{SM}_{\mathrm{f}}$ at $37{ }^{\circ} \mathrm{C}$ in the presence of liposomes $\left(10 \mathrm{mg} \mathrm{mL}^{-1}\right.$, diphytanoylphosphatidylcholine, DPhPC), which produced a new band upon sodium dodecyl sulfate/polyacrylamide gel electrophoresis (SDS-PAGE) corresponding to the size $(\sim 240$ $\mathrm{kDa}$ ) of the heptamer (Figure 1F, left). We also incubated $\mathrm{SM}_{\mathrm{f}}$ in the presence of rabbit red blood cell membranes ( $\mathrm{rRBCm}$ ) in different ratios with radiolabeled WT $\alpha \mathrm{HL}$ produced by IVTT. The $\mathrm{SM}_{\mathrm{f}}$ oligomerized to form heteroheptamers with 
A
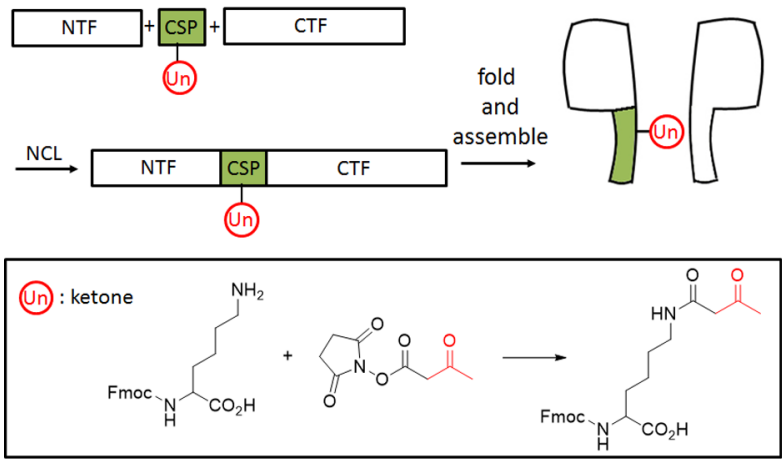

C

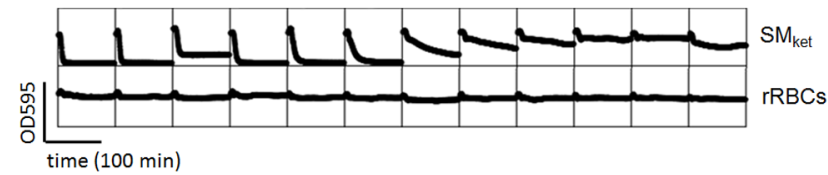

B

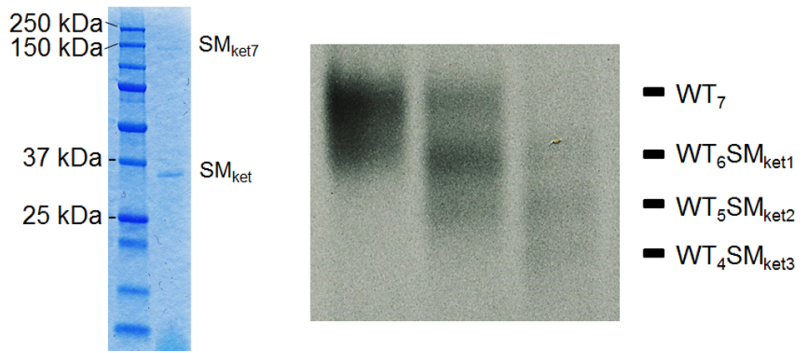

Figure 3. Preparation of $\alpha \mathrm{HL}$ pores containing an unnatural amino acid. (A) An $\alpha \mathrm{HL}$ monomer was synthesized from three fragments with a central segment (CSP) bearing an unnatural amino acid with a side chain bearing a ketone group (inset: Un, Fmoc- ${ }^{6}$-(3-oxobutanoyl)lysine, Fmoc-Ket-OH). (B) Characterization of the synthetic $\alpha \mathrm{HL}$ monomer $\left(\mathrm{SM}_{\mathrm{ket}}\right)$ by LC-MS. $[\mathrm{M}+\mathrm{H}]^{+}=35109$ (obs), 35107 (calcd). (C) Hemolysis assay for $\mathrm{SM}_{\text {ket }}$. The full-length synthetic $\alpha \mathrm{HL}$ monomer $\left[\mathrm{SM}_{\mathrm{ket}}\left(0.31 \mathrm{mg} \mathrm{mL}{ }^{-1}\right)\right]$ lysed rRBCs. rRBCs alone (row 6 in Figure $2 \mathrm{E}$ ) are displayed for comparison. (D) Homo- (left) and hetero- (right) heptameric pores formed with $\mathrm{SM}_{\mathrm{ket}}$. $\mathrm{The}$ pores were prepared by the same methods described in Figure 1F,G.

different stoichiometries $\left(\mathrm{WT}_{7-n} \mathrm{SM}_{n}, n=0-7\right)$ (Figure $1 \mathrm{~F}$, right). $\mathrm{SM}_{\triangle 6-113 \mathrm{M}}$ and $\mathrm{SM}_{\triangle 6-113 \mathrm{~F}}$ were incubated with $\mathrm{DPhPC}$ liposomes $\left(10 \mathrm{mg} \mathrm{mL}^{-1}\right)$ and oligomerized to form homomeric structures $^{11}$ (Figure 1G).

Electrical Properties of Two-Fragment Pores and Binding of Cyclodextrins. To examine the electrical properties of the various heptameric $\alpha \mathrm{HL}$ pores containing synthetic subunits $\left[\mathrm{WT}_{6} \mathrm{SM}_{\mathrm{f} 1},\left(\mathrm{SM}_{\Delta 6-113 \mathrm{M}}\right)_{7}\right.$, and $\left.\left(\mathrm{SM}_{\Delta 6-113 \mathrm{~F}}\right)_{7}\right]$, we determined the mean unitary conductance values under defined conditions and measured $I-V$ curves (Figure S10a,b). The conductance values for the $\alpha \mathrm{HL}$ pores containing synthetic monomers were similar to that of pores comprising WT $\alpha \mathrm{HL}$ subunits produced by IVTT.

To confirm that the transmembrane $\beta$ barrels of the semisynthetic pores were intact, we evaluated the binding kinetics at the single-molecule level of cyclodextrin molecular adapters ( $\beta \mathrm{CD}$ and $\mathrm{am}_{7} \beta \mathrm{CD}$ (heptakis(6-deoxy-6-amino)- $\beta$ cyclodextrin $)$ ) with the $\mathrm{WT}_{6}\left(\mathrm{SM}_{\mathrm{f}}\right)_{1},\left(\mathrm{SM}_{\Delta 6-113 \mathrm{M}}\right)_{7}$, and $\left(\mathrm{SM}_{\Delta 6-113 \mathrm{~F}}\right)_{7}$ pores. $^{25,26}$ It was already known that the homoheptamer formed from TBM $\Delta 6 / \mathrm{M} 113 \mathrm{~F}$ binds $\mathrm{am}_{7} \beta \mathrm{CD}$ very tightly. ${ }^{19,20}$ We determined the association and dissociation rate constants $\left(k_{\text {on }}\right.$ and $\left.k_{\text {off }}\right)$ of $\beta C D$ for the three different protein pores. At least three measurements were made for each construct. $\beta \mathrm{CD}$ blocks the ionic current transiently when it is lodged within the lumen of the $\alpha \mathrm{HL}$ pore. The dissociation constants $\left(K_{\mathrm{D}}=k_{\text {off }} / k_{\text {on }}\right.$, Figure S11) of $\beta \mathrm{CD}$ for $\mathrm{WT}_{6} \mathrm{SM}_{\mathrm{f} 1}\left(K_{\mathrm{D}}\right.$ $=14.5 \pm 0.4 \times 10^{-3} \mathrm{M}, k_{\text {on }}=10.0 \pm 0.2 \times 10^{4} \mathrm{M}^{-1} \cdot \mathrm{s}^{-1}$, and $k_{\text {off }}$ $\left.=14.5 \pm 0.2 \times 10^{2} \mathrm{~s}^{-1}\right)$ and $\left(\mathrm{SM}_{\Delta 6-113 \mathrm{M}}\right)_{7}\left(K_{\mathrm{D}}=6.5 \pm 0.2 \times\right.$ $10^{-2} \mathrm{M}, k_{\text {on }}=2.4 \pm 0.1 \times 10^{4} \mathrm{M}^{-1} \cdot \mathrm{s}^{-1}$, and $k_{\text {off }}=15.7 \pm 0.3 \times$ $10^{2} \mathrm{~s}^{-1}$ ) were similar to the values obtained in our previous studies for $\mathrm{WT}_{7}{ }^{25}$ and $\left(\mathrm{TBM}_{\Delta 6-113 \mathrm{M}}\right)_{7}{ }^{19}$ The $K_{\mathrm{D}}(6.1 \pm 1.3 \times$ $\left.10^{-5} \mathrm{M}\right)$ of $\beta \mathrm{CD}$ for $\left(\mathrm{SM}_{\Delta 6-113 \mathrm{~F}}\right)_{7}$ (Figure S12A) was smaller by 3 orders of magnitude than the $K_{\mathrm{D}}$ for the $\left(\mathrm{SM}_{\Delta 6-113 \mathrm{M}}\right)_{7}$ pore, which makes sense as it is known that $\beta \mathrm{CD}$ binds more tightly by 3-4 orders of magnitude to a pore formed by the full-length M113F subunit than it does to the WT pore. ${ }^{20} \mathrm{We}$ also analyzed the binding of $\mathrm{am}_{7} \beta \mathrm{CD}$ to the $\left(\mathrm{SM}_{\Delta 6-113 \mathrm{~F}}\right)_{7}$ pore (Figure S12B) and found that it remained bound to the pore "permanently" as previously reported for the same truncated pore produced by conventional means. ${ }^{19}$ The binding kinetics of $\beta \mathrm{CD}$ and $\mathrm{am}_{7} \beta \mathrm{CD}$ suggest that the semisynthetic protein pores produced by two-fragment coupling, and thereby containing a Cys mutation (S114C), are very similar to the protein pores derived from WT $\alpha \mathrm{HL}$ produced directly by IVTT from the corresponding genes.

Two-Fragment Ligation Forms a Native Amide Bond. To verify the existence of a native amide bond formed between Gly126 and Cys127 in $\mathrm{SM}_{\mathrm{f}}$, we carried out thiolate chemistry on single $\mathrm{WT}_{6} \mathrm{SM}_{\mathrm{f} 1}$ pores by using the side chain of Cys-127 generated by NCL. In the absence of methyl-PEG-OPSS $(\mathrm{MPO}, 5.0 \mathrm{kDa})$, the open state of $\mathrm{WT}_{6} \mathrm{SM}_{\mathrm{f} 1}$ had a long duration $(>30 \mathrm{~min})$. The addition of MPO $(0.1 \mathrm{mM})$ to the trans compartment at $+100 \mathrm{mV}$ generated an irreversible current drop (Figure 2A), due to the formation of a disulfide bond between MPO and the side chain of Cys-127. The pore remained blocked over a range of potentials $(-100$ to +100 $\mathrm{mV}$ ), indicating that the current drop is not due to simple clogging of the pore. In the presence DTT $(5 \mathrm{mM}$, both compartments), the open current level was restored (Figure 2B) because the PEG chain was cleaved from the pore.

Three-Fragment Ligation To Form a Ketone-Containing $\alpha \mathrm{HL}$ Polypeptide. With $\mathrm{NTF}_{113 \mathrm{M}}$ and $\mathrm{CTF}_{127}$, and a synthetic central peptide, we next carried out three-fragment coupling to construct a full-length $\alpha \mathrm{HL}$ monomer containing a ketone group (Figure $3 \mathrm{~A}$ ). The ketone is a versatile functional group in organic chemistry and participates in a large number of reactions. ${ }^{27-30}$ However, reactions of a ketone have not been observed yet at the single-molecule level. The synthetic 
A
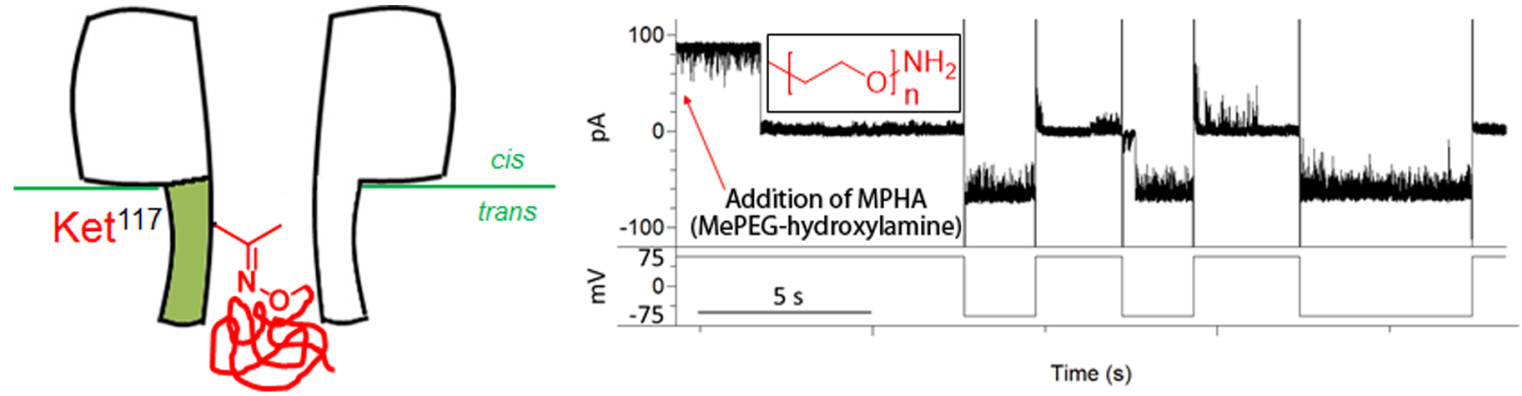

B
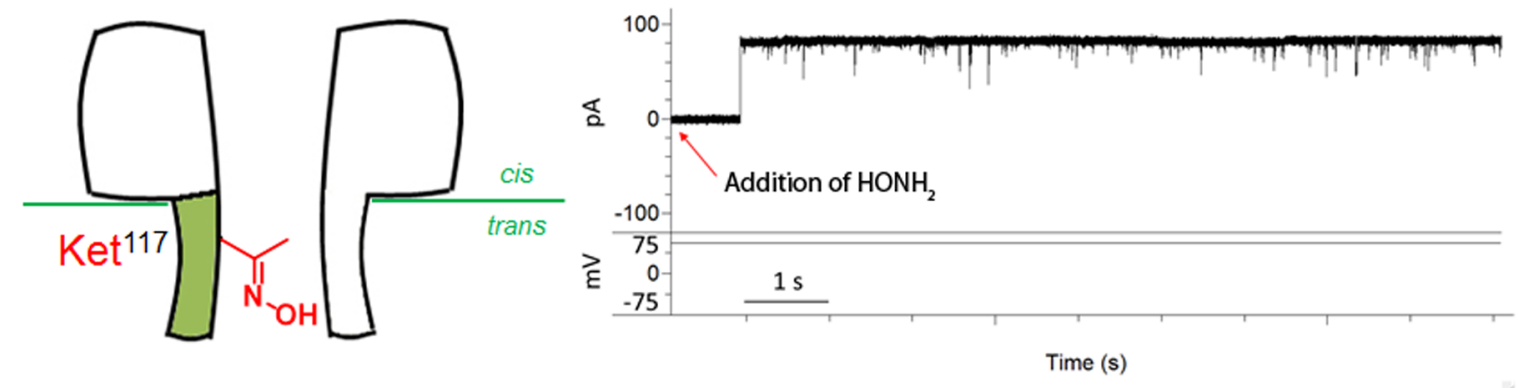

$\mathrm{C}$

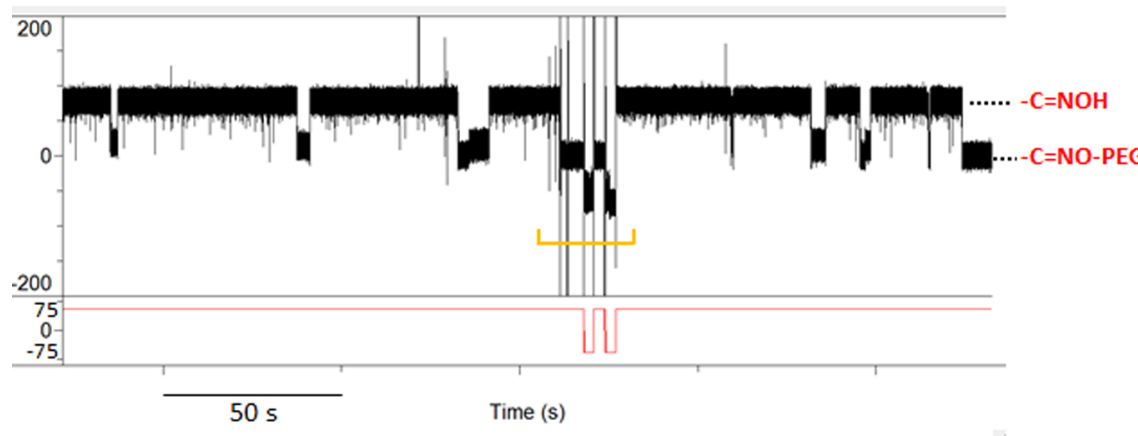

D

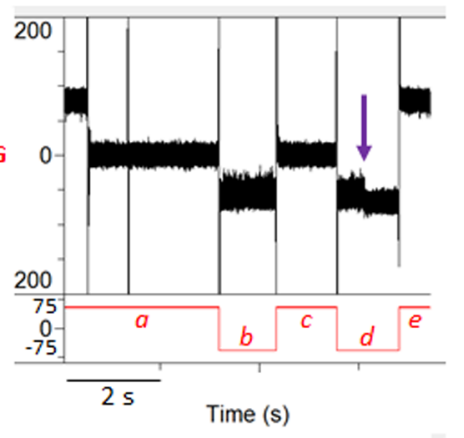

Figure 4. Single-molecule reactions of the $\mathrm{WT}_{6} \mathrm{SM}_{\mathrm{ket1}}$ pore. (A) A WT $\mathrm{SM}_{\text {ket1 }}$ pore was reacted with MePEG-hydroxylamine (MPHA, 1.1 kDa, $2 \mathrm{mM}$, inset) added to the trans compartment. Reaction occurred at a positive potential $(+75 \mathrm{mV})$ and led to a permanent current blockade of the $\mathrm{WT}_{6} \mathrm{SM}_{\text {ket1 }}$ pore. The modified pore only opened at negative applied potentials. (B) The pore was restored to an open state when $20 \mathrm{mM}$ $\mathrm{HONH}_{2} \cdot \mathrm{HCl}$ was added to both compartments to release the PEG chain. The currents in (A) and (B) were filtered at $5 \mathrm{kHz}$ and sampled at $25 \mathrm{kHz}$. For display, further digital filtering was carried out at $2 \mathrm{kHz}$ with an 8-pole low-pass Bessel filter. The buffer was $1 \mathrm{M} \mathrm{KCl,} 50 \mathrm{mM} \mathrm{Na}$ acetate $(\mathrm{pH} 3.4)$. (C) Reversible oxime formation in a single synthetic pore containing a ketone $\left(\mathrm{WT}_{6} \mathrm{SM}_{\mathrm{ket1}}\right)$. Oxime formation with MPHA leads to a current drop, while reversal with $\mathrm{HONH}_{2}$ returns the current to its initial level. The section defined by the orange bracket is magnified in panel D. (D) Negative potential $(-75 \mathrm{mV}, b)$ was applied during the PEG-oxime state (a), which opened the pore (residual current, $\left.I_{\mathrm{RES}}=91 \%\right)$. Subsequently, a positive potential $(+75 \mathrm{mV}, c)$ was applied, and the pore closed. The pore became fully open (violet arrow) with $I_{\mathrm{RES}}=100 \%$ at negative potential $(-75 \mathrm{mV}, d)$, presumably when the formation of an oxime with $\mathrm{HONH}_{2}$ led to release of the pore-bound polymer. The pore was restored to an open state at a positive potential $(+75 \mathrm{mV}, e)$.

methods used to obtain an unnatural amino acid containing a ketone group ${ }^{28,29}$ are not very efficient, and the techniques ${ }^{27,30}$ used to incorporate a ketone amino acid into the middle of a polypeptide chain are often arduous. We made an unnatural amino acid bearing a ketone (Fmoc-Ket-OH; Fmoc-N ${ }^{6}-(3-$ oxobutanoyl)lysine), Figure 3A, inset) from Fmoc-Lys-OH and $\mathrm{N}$-hydroxysuccinimidyl acetoacetate (NHA). Fmoc-Ket-OH was used for SPPS of a central segment of the polypeptide chain (CSP: Thz ${ }^{114}$ ThrLeuKetTyrGlyPheAsnGlyAsnValThrGly $\left.{ }^{126}-\mathrm{Nbz}\right)$, such that the Ket side chain would project into the transmembrane $\beta$ barrel of an $\alpha \mathrm{HL}$ pore. CSP was prepared with a C-terminal acylurea ${ }^{31}$ (Figures S13 and S14), which yields a peptide arylthioester with 4-mercaptophenylacetic acid (MPAA), accelerating the NCL reaction. We then proceeded to assemble a full-length $\alpha \mathrm{HL}$ bearing the ketone group with two sequential NCL reactions (Figure S15). The final product $\left(\mathrm{SM}_{\mathrm{ket}}\right)$ was purified (Figure S16) and characterized by LC-MS (Figure 3B and Figure S9D; $[\mathrm{M}+$ $\mathrm{H}]^{+}=35109$ (obs), $35107 \mathrm{Da}$ (calcd)). A hemolysis assay showed that folded $\mathrm{SM}_{\mathrm{ket}}\left(\mathrm{HC}_{50}=47 \mathrm{ng} \mathrm{mL}{ }^{-1}\right)$ had similar activity to the WT $\alpha \mathrm{HL}$ monomer (Figure 3C). $\mathrm{SM}_{\mathrm{ket}}$ also formed homo- and heteroheptameric pores in the presence of liposomes and $\mathrm{rRBCm}$, respectively (Figure 3D).

We determined the mean unitary conductance values for individual $\mathrm{WT}_{6} \mathrm{SM}_{1 \text { ket }}$ pores in $1 \mathrm{M} \mathrm{KCl}$ and $50 \mathrm{mM} \mathrm{Na}$ acetate buffer over a range of applied potentials $(-100$ to $+100 \mathrm{mV})$ (Figure S18A). The buffer was adjusted to $\mathrm{pH} 3.4$ in anticipation of an acid-catalyzed addition reaction (imine formation) on the ketone side chain (see below). The conductance of $\mathrm{WT}_{6} \mathrm{SM}_{\text {ket1 }}(0.93 \pm 0.10 \mathrm{nS}, n=9)$ at +100 $\mathrm{mV}$ was similar to that of the $\mathrm{WT}_{7}$ pore $(1.07 \pm 0.02 \mathrm{nS}, n=9)$ under the same conditions. We also determined the association and dissociation rate constants at $\mathrm{pH} 3.4\left(k_{\text {on }}\right.$ and $\left.k_{\text {off }}\right)$ for $\beta \mathrm{CD}$ binding from the values of the mean dwell times $\left(\tau_{\text {on }}\right.$ and $\left.\tau_{\text {off }}\right)$ 
$\left[\mathrm{WT}_{7}: K_{\mathrm{D}}=6.1 \pm 0.2 \times 10^{-2} \mathrm{M}(n=3), k_{\text {on }}=71.7 \pm 0.1 \times 10^{2}\right.$ $\mathrm{M}^{-1} \cdot \mathrm{s}^{-1}$, and $k_{\text {off }}=4.4 \pm 0.2 \times 10^{2} \mathrm{~s}^{-1} ; \mathrm{WT}_{6} \mathrm{SM}_{\mathrm{ket} 1}: K_{\mathrm{D}}=8.6 \pm$ $0.7 \times 10^{-2} \mathrm{M}(n=3), k_{\text {on }}=83.7 \pm 6.8 \times 10^{2} \mathrm{M}^{-1} \cdot \mathrm{s}^{-1}$, and $k_{\text {off }}=$ $7.2 \pm 0.1 \times 10^{2} \mathrm{~s}^{-1}$ ] (Figure S17). The ketone residue presented by the SM subunit affects neither the electrical properties of the $\alpha \mathrm{HL}$ pore nor its ability to bind the $\beta \mathrm{CD}$ adaptor.

Single-Molecule Covalent Chemistry with a KetoneContaining $\alpha \mathrm{HL}$ Pore. We then carried out imine chemistry with single $\mathrm{WT}_{6} \mathrm{SM}_{1 \mathrm{ket}}$ pores. We first examined the interaction of the $\mathrm{WT}_{7}$ pore with $1.1 \mathrm{kDa}$ MePEG-hydroxylamine (MPHA). The addition of $2 \mathrm{mM}$ MPHA to the trans compartment at $+75 \mathrm{mV}$ in the presence of $1 \mathrm{M} \mathrm{KCl}, 50$ $\mathrm{mM} \mathrm{Na}$ acetate buffer ( $\mathrm{pH} 3.4$ ), produced short blockades $(\sim 100 \mu \mathrm{s})$, which arise from the entry of MPHA into the lumen of the pore without covalent attachment. ${ }^{32}$ No prolonged current decrease was observed with the $\mathrm{WT}_{7}$ pore during $2 \mathrm{~h}$ of monitoring. We then added $2 \mathrm{mM}$ MPHA to the trans side of the $\mathrm{WT}_{6} \mathrm{SM}_{\text {ket1 }}$ pore, under the same conditions, which led to a permanent current blockade at $+75 \mathrm{mV}$ within $10 \mathrm{~min}$, presumably due to the covalent attachment of MPHA to the ketone group within the pore through imine formation. Interestingly, the modified $\mathrm{WT}_{6} \mathrm{SM}_{\text {ket1 }}$ pore opened at negative applied potentials $\left(-100\right.$ to $0 \mathrm{mV}$ ) with $I_{\mathrm{RES}}=91 \%$ (residual current), compared with the original open state. By contrast, at positive potentials $(0$ to $+100 \mathrm{mV})$, the pore was almost closed $\left(I_{\mathrm{RES}}=3.2 \%\right.$, Figure S18B) with very short openings $(<50 \mathrm{~ms})$. It follows that the current-voltage $(I-V)$ characteristics of $\mathrm{WT}_{6} \mathrm{SM}_{\mathrm{ket1}}$-imine-PEG show virtually complete current rectification (Figure S18B). Previously, we developed a diode-like $\alpha \mathrm{HL}$ pore (7R- $\alpha \mathrm{HL}$ ) with positively charged Arg side chains projecting into the lumen of the transmembrane $\beta$ barrel, ${ }^{33}$ allowing ions to flow only at positive potentials. We used $7 \mathrm{R}$ $\alpha \mathrm{HL}$ to construct a bridge rectifier circuit from droplet interface bilayers. Therefore, the $\mathrm{WT}_{6} \mathrm{SM}_{\text {ket } 1}$-oxime-PEG pore, which shows the opposite electrical properties to 7R- $\alpha \mathrm{HL}$ (Figure $4 \mathrm{~A})$, might be used in related applications. To confirm that the attachment was through imine formation, we added $20 \mathrm{mM}$ $\mathrm{NH}_{2} \mathrm{OH}$ to both compartments to cleave the linkage. In $\sim 15$ $\mathrm{min}$, the current returned to its initial level (Figure 4B), suggesting that the PEG chain had been cleaved from the pore.

The observation of the ability of the $\mathrm{WT}_{6} \mathrm{SM}_{\text {ket1 }}$ pore to return its initial conductance level led us to investigate an oxime-oxime exchange reaction on the ketone side chain at the single-molecule level. In the presence of $2 \mathrm{mM} \mathrm{MPA}$, in the trans compartment, and $10 \mathrm{mM}$ of $\mathrm{HONH}_{2}$, in both the cis and trans compartment, a reversible reaction was observed (Figure 4C). During the formation of the $O$-alkyloxime by MPHA, the current was greatly reduced to levels in the range of 1.5 to 17 pA (Figure 4C). Subsequent transitions between this "closed" level and the open level were apparent. The open level represents the formation of an oxime with $\mathrm{HONH}_{2}$, and release of the PEG chain from the pore. The formation of an $\mathrm{O}$ alkyloxime within the pore with MPHA only allowed substantial ion flow at a negative potential $(-75 \mathrm{mV})$ (orange bracket in Figure 4C and $\mathrm{a}-\mathrm{d}$ in Figure 4D). After transoximination with $\mathrm{HONH}_{2},{ }^{34}$ the current increased from -56 to $-67 \mathrm{pA}$ at $-75 \mathrm{mV}$ (violet arrow in Figure 4D) and an open-level current of $+78 \mathrm{pA}$ was observed during the subsequent application of a positive potential $(+75 \mathrm{mV})$.

The mean dwell time of the open pore $\left(\tau_{\text {on }}\right)$ is the mean lifetime of the oxime formed by $\mathrm{HONH}_{2}$ (o), which is the mean reaction time for $\mathrm{O}$-alkyloxime (ao) formation with
MPHA. Similarly, the mean dwell time of the closed pore $\left(\tau_{\text {off }}\right)$ is the mean lifetime of the $O$-alkyloxime, which is the mean reaction time for oxime formation with $\mathrm{HONH}_{2}$. The measured mean lifetimes the $O$-alkyloxime and the oxime were $52 \pm 2 \mathrm{~s}$ $(\mathrm{n}=79)$ and $51 \pm 2 \mathrm{~s}(\mathrm{n}=78)$ (Figure S19), which yield rate constants for transoximination of $\mathrm{k}_{\mathrm{f}, \mathrm{oo}}=10 \mathrm{M}^{-1} \cdot \mathrm{s}^{-1}$ and $\mathrm{k}_{\mathrm{f}, \mathrm{o}}=2$ $\mathrm{M}^{-1} \cdot \mathrm{s}^{-1}$, respectively, in $1 \mathrm{M} \mathrm{KCl}, \mathrm{Na}$ acetate buffer ( $\mathrm{pH} 3.4$ ), at $+75 \mathrm{mV}$, where $\mathrm{k}_{\mathrm{f}, \mathrm{ao}}=\mathrm{k}_{\mathrm{on}}=1 / \tau_{\mathrm{on}} \cdot[\mathrm{MPHA}]$ and $\mathrm{k}_{\mathrm{f}, \mathrm{o}}=\mathrm{k}_{\mathrm{off}}=$ $1 / \tau_{\text {off }}\left[\mathrm{NH}_{2} \mathrm{OH}\right]$.

\section{CONCLUSIONS}

The ability to introduce unnatural amino acids into the $\alpha \mathrm{HL}$ pore has the potential to provide a large variety of reactive side chains for the investigation of single-molecule covalent chemistry. We have previously produced $\alpha \mathrm{HL}$ polypeptides with unnatural alkyl and aryl amino acids by using in vitro chemically acylated tRNAs. ${ }^{35}$ However, this approach is demanding and often gives poor results when more than one amino acid is introduced. The coupling of polypeptide segments by NCL has been used extensively to produce proteins $^{36-38}$ and is a favorable alternative means to incorporate unnatural amino acids. In the present work, we demonstrate a variety of synthetic protein pores using $\alpha \mathrm{HL}$ polypeptides and use the synthetic pore containing a ketone as single-molecule nanoreactor.

Oxime chemistry was examined in an aqueous environment at the single-molecule level with a ketone-containing $\alpha \mathrm{HL}$ pore $\left(\mathrm{WT}_{6} \mathrm{SM}_{\mathrm{ket} 1}\right)$, and the work described here is the first observation of reversible covalent chemistry using an unnatural amino acid side-chain in a nanoreactor. Oxime formation from a ketone proceeds via nucleophilic addition to form a tetrahedral intermediate, ${ }^{39,40}$ followed by the elimination of water. Transoximination also proceeds reversibly through a tetrahedral intermediate that subsequently breaks down to form a new oxime and a hydroxylamine. ${ }^{34}$ In our work, no intermediates were observed in both the $\mathrm{O}$-alkyloxime formation by MPHA and the transoximination reaction. Presumably, the lifetimes of the tetrahedral intermediates are too short or the current changes too small to observe under our recording conditions. We obtained rate constants for oxime and $O$-alkyloxime formation within the pore $\left(\mathrm{k}_{\mathrm{f}, \mathrm{ao}}=10 \mathrm{M}^{-1} \cdot \mathrm{s}^{-1}\right.$ and $\left.\mathrm{k}_{\mathrm{f}, \mathrm{o}}=2 \mathrm{M}^{-1} \cdot \mathrm{s}^{-1}\right)$. Earlier determinations in bulk solution ${ }^{41,42}$ are in the range $\sim 1$ to $10^{4} \cdot \mathrm{M}^{-1} \cdot \mathrm{s}^{-1}$ and depend strongly on substituents, solvent, $\mathrm{pH}$, and temperature. In our case, the partitioning of the polymer reactant, MPHA, into the pore must be considered. ${ }^{11,43}$

We have observed oxime formation by using a semisynthetic pore containing an unnatural amino acid as a nanoreactor. The ketone-containing pore expands the range of covalent chemistry that can be studied by the nanoreactor approach to reversible reactions for which statistically significant data can be acquired rapidly without tedious repeats. Taken together with our recent demonstration of alkyne chemistry, ${ }^{11}$ the versatility of the nanoreactor approach is apparent, and we look forward to developing even more ambitious possibilities, such as singlemolecule catalysis, which may require the placement of several different unnatural amino acids within a single polypeptide chain.

\section{METHODS}

Native Chemical Ligation. Two-Fragment Coupling. Fifty microliters of CTF $(>0.5 \mathrm{mM})$, from which pyruvate had been removed, was mixed with $50 \mu \mathrm{L}$ of NTF $(>0.5 \mathrm{mM})$ in $0.4 \mathrm{~mL}$ of NCL 
buffer [200 $\mathrm{mM} \mathrm{NaH} \mathrm{PO}_{4}(\mathrm{pH} 6.9)$ containing $6 \mathrm{M} \mathrm{Gu} \cdot \mathrm{HCl}$, $50 \mathrm{mM}$ tris(2-carboxyethyl)phosphine (TCEP), and $200 \mathrm{mM}$ 4-mercaptophenylacetic acid (MPAA)] and concentrated to $100 \mu \mathrm{L}$ using a centrifugal filter (Amicon, MWCO 3k) at $14000 \mathrm{~g}$ for $20 \mathrm{~min}$. The buffer containing NTF and CTF was replaced with NCL buffer by repeated ( 5 times) dilution and concentration with the same filter. The reaction was allowed to proceed overnight at room temperature.

Three-Fragment Coupling. CTF $(0.5 \mathrm{mM})$, from which pyruvate had been removed, was mixed with CSP-Nbz $(5 \mathrm{mM})$ in $0.5 \mathrm{~mL}$ of $\mathrm{NCL}$ buffer $\left[200 \mathrm{mM} \mathrm{NaH} \mathrm{PO}_{4}(\mathrm{pH} 6.9)\right.$ containing $6 \mathrm{M} \mathrm{Gu} \cdot \mathrm{HCl}, 50$ $\mathrm{mM}$ tris(2-carboxyethyl)phosphine (TCEP), and $50 \mathrm{mM}$ MPAA]. After overnight reaction at room temperature, the unreacted peptide was removed by passing the mixture through a size-exclusion column (Superdex 200 10/300 GL). The product was analyzed by LC-MS.

The N-terminal Thz group was subsequently cleaved by treatment with $0.4 \mathrm{M} \mathrm{HONH}_{2} \cdot \mathrm{HCl}$ in $200 \mathrm{mM} \mathrm{NaH} \mathrm{PO}_{4}$ buffer ( $\mathrm{pH}$ adjusted to 4.0) containing $6 \mathrm{M} \mathrm{Gu} \cdot \mathrm{HCl}$ and $50 \mathrm{mM}$ TCEP for $4 \mathrm{~h}$ at room temperature. For the next round of ligation, the buffer was replaced with NCL buffer containing $200 \mathrm{mM}$ MPAA by repeated dilution and concentration with a centrifugal filter (Amicon, MWCO 3k). NTF- ${ }^{\alpha}$ thioester $(0.6 \mathrm{mM})$ was mixed with the first ligation product $(0.3 \mathrm{mM})$, and the reaction was allowed to proceed overnight. The final ligation product was purified by gel filtration followed by ionexchange chromatography. The reaction yield was determined by quantifying the intensity of the polypeptide bands after SDS-PAGE by using Image $(\mathrm{NIH})$.

\section{ASSOCIATED CONTENT}

\section{S Supporting Information}

The Supporting Information is available free of charge on the ACS Publications website at DOI: 10.1021/acsnano.6b04663.

Experimental procedures and supplementary figures for analytical and spectral characterization data (PDF)

\section{AUTHOR INFORMATION}

\section{Corresponding Author}

*E-mail: hagan.bayley@chem.ox.ac.uk.

\section{Author Contributions}

J. Lee, A.J.B., M.A.B., S.C., O.D., and H.B. designed the research. A.J.B., M.A.B., S.C., and O.D. carried out early synthetic work. J. Lee performed recent synthetic work and characterization of the synthetic pores. J. Li and H.T. assisted with solid-phase peptide synthesis. J. Lee and H.B. wrote the manuscript.

\section{Notes}

The authors declare no competing financial interest.

\section{ACKNOWLEDGMENTS}

The authors thank Professor Tom Muir (Princeton University) for helpful discussions. This work was supported by an ERC Advanced Grant. J. Lee was supported in part by a Korean government scholarship. O.D. was supported by a Junior Research Fellowship at Christ Church, Oxford. This paper is dedicated to the memory of Dr. Stephen Cheley.

\section{REFERENCES}

(1) Song, L.; Hobaugh, M. R.; Shustak, C.; Cheley, S.; Bayley, H.; Gouaux, J. E. Structure of Staphylococcal Alpha-Hemolysin, a Heptameric Transmembrane Pore. Science 1996, 274, 1859-66.

(2) Bayley, H.; Luchian, T.; Shin, S.-H.; Steffensen, M. SingleMolecule Covalent Chemistry in a Protein Nanoreactor. In Single Molecules and Nanotechnology; Rigler, R., Vogel, H., Eds.; Springer: Berlin, 2008; Vol. 12, pp 251-277.
(3) Lu, S.; Li, W. W.; Rotem, D.; Mikhailova, E.; Bayley, H. A Primary Hydrogen-Deuterium Isotope Effect Observed at the SingleMolecule Level. Nat. Chem. 2010, 2, 921-8.

(4) Steffensen, M. B.; Rotem, D.; Bayley, H. Single-Molecule Analysis of Chirality in a Multicomponent Reaction Network. Nat. Chem. 2014, 6, 603-7.

(5) Pulcu, G. S.; Mikhailova, E.; Choi, L.-S.; Bayley, H. Continuous Observation of the Stochastic Motion of an Individual Small-Molecule Walker. Nat. Nanotechnol. 2015, 10, 76-83.

(6) Shin, S. H.; Luchian, T.; Cheley, S.; Braha, O.; Bayley, H. Kinetics of a Reversible Covalent-Bond-Forming Reaction Observed at the Single-Molecule Level. Angew. Chem., Int. Ed. 2002, 41, 3707-9.

(7) Shin, S. H.; Bayley, H. Stepwise Growth of a Single Polymer Chain. J. Am. Chem. Soc. 2005, 127, 10462-10463.

(8) Choi, L. S.; Bayley, H. S-Nitrosothiol Chemistry at the SingleMolecule Level. Angew. Chem., Int. Ed. 2012, 51, 7972-7976.

(9) Hammerstein, A. F.; Shin, S. H.; Bayley, H. Single-Molecule Kinetics of Two-Step Divalent Cation Chelation. Angew. Chem., Int. Ed. 2010, 49, 5085-90.

(10) Boersma, A. J.; Bayley, H. Continuous Stochastic Detection of Amino Acid Enantiomers with a Protein Nanopore. Angew. Chem., Int. Ed. 2012, 51, 9606-9.

(11) Lee, J.; Bayley, H. Semisynthetic Protein Nanoreactor for Single-Molecule Chemistry. Proc. Natl. Acad. Sci. U. S. A. 2015, 112, 13768-73.

(12) Chong, S. R.; Mersha, F. B.; Comb, D. G.; Scott, M. E.; Landry, D.; Vence, L. M.; Perler, F. B.; Benner, J.; Kucera, R. B.; Hirvonen, C. A.; Pelletier, J. J.; Paulus, H.; Xu, M. Q. Single-Column Purification of Free Recombinant Proteins Using a Self-Cleavable Affinity Tag Derived from a Protein Splicing Element. Gene 1997, 192, 271-281.

(13) Evans, T. C.; Benner, J.; Xu, M. Q. Semisynthesis of Cytotoxic Proteins Using a Modified Protein Splicing Element. Protein Sci. 1998, 7, 2256-2264.

(14) Wu, W.; Wood, D. W.; Belfort, G.; Derbyshire, V.; Belfort, M. Intein-Mediated Purification of Cytotoxic Endonuclease I-Tevi by Insertional Inactivation and $\mathrm{Ph}$-Controllable Splicing. Nucleic Acids Res. 2002, 30, 4864-71.

(15) Tolbert, T. J.; Wong, C. H. New Methods for Proteomic Research: Preparation of Proteins with N-Terminal Cysteines for Labeling and Conjugation. Angew. Chem., Int. Ed. 2002, 41, 2171-4.

(16) Pentelute, B. L.; Barker, A. P.; Janowiak, B. E.; Kent, S. B. H.; Collier, R. J. A Semisynthesis Platform for Investigating Structure Function Relationships in the N-Terminal Domain of the Anthrax Lethal Factor. ACS Chem. Biol. 2010, 5, 359-364.

(17) Gentle, I. E.; De Souza, D. P.; Baca, M. Direct Production of Proteins with N-Terminal Cysteine for Site-Specific Conjugation. Bioconjugate Chem. 2004, 15, 658-63.

(18) Bang, D.; Kent, S. B. A One-Pot Total Synthesis of Crambin. Angew. Chem., Int. Ed. 2004, 43, 2534-8.

(19) Stoddart, D.; Ayub, M.; Hofler, L.; Raychaudhuri, P.; Klingelhoefer, J. W.; Maglia, G.; Heron, A.; Bayley, H. Functional Truncated Membrane Pores. Proc. Natl. Acad. Sci. U. S. A. 2014, 111, 2425-30.

(20) Gu, L. Q.; Cheley, S.; Bayley, H. Prolonged Residence Time of a Noncovalent Molecular Adapter, Beta-Cyclodextrin, within the Lumen of Mutant Alpha-Hemolysin Pores. J. Gen. Physiol. 2001, 118, 481493.

(21) Howorka, S.; Bayley, H. Improved Protocol for HighThroughput Cysteine Scanning Mutagenesis. Biotechniques 1998, 25, 764-6.

(22) Hackeng, T. M.; Griffin, J. H.; Dawson, P. E. Protein Synthesis by Native Chemical Ligation: Expanded Scope by Using Straightforward Methodology. Proc. Natl. Acad. Sci. U. S. A. 1999, 96, 1006810073.

(23) Lee, J.; Kwon, Y.; Pentelute, B. L.; Bang, D. Use of Model Peptide Reactions for the Characterization of Kinetically Controlled Ligation. Bioconjugate Chem. 2011, 22, 1645-1649.

(24) Walker, B.; Krishnasastry, M.; Zorn, L.; Kasianowicz, J.; Bayley, H. Functional Expression of the Alpha-Hemolysin of Staphylococcus 
Aureus in Intact Escherichia Coli and in Cell Lysates. Deletion of Five C-Terminal Amino Acids Selectively Impairs Hemolytic Activity. J. Biol. Chem. 1992, 267, 10902-10909.

(25) Gu, L. Q.; Bayley, H. Interaction of the Non-Covalent Molecular Adapter, Beta-Cyclodextrin, with the Staphylococcal Alpha-Hemolysin Pore. Biophys. J. 2000, 79, 1967-1975.

(26) Braha, O.; Webb, J.; Gu, L. Q.; Kim, K.; Bayley, H. Carriers versus Adapters in Stochastic Sensing. ChemPhysChem 2005, 6, 889892.

(27) Cornish, V. W.; Hahn, K. M.; Schultz, P. G. Site-Specific Protein Modification Using a Ketone Handle. J. Am. Chem. Soc. 1996, 118, $8150-8151$

(28) Mahal, L. K.; Yarema, K. J.; Bertozzi, C. R. Engineering Chemical Reactivity on Cell Surfaces through Oligosaccharide Biosynthesis. Science 1997, 276, 1125-1128.

(29) Ayers, B.; Blaschke, U. K.; Camarero, J. A.; Cotton, G. J.; Holford, M.; Muir, T. W. Introduction of Unnatural Amino Acids into Proteins Using Expressed Protein Ligation. Biopolymers 1999, 51, 343-354.

(30) Wang, L.; Zhang, Z.; Brock, A.; Schultz, P. G. Addition of the Keto Functional Group to the Genetic Code of Escherichia Coli. Proc. Natl. Acad. Sci. U. S. A. 2003, 100, 56-61.

(31) Blanco-Canosa, J. B.; Dawson, P. E. An Efficient Fmoc-Spps Approach for the Generation of Thioester Peptide Precursors for Use in Native Chemical Ligation. Angew. Chem., Int. Ed. 2008, 47, 6851-5.

(32) Movileanu, L.; Cheley, S.; Bayley, H. Partitioning of Individual Flexible Polymers into a Nanoscopic Protein Pore. Biophys. J. 2003, 85, 897-910.

(33) Maglia, G.; Heron, A. J.; Hwang, W. L.; Holden, M. A.; Mikhailova, E.; Li, Q. H.; Cheley, S.; Bayley, H. Droplet Networks with Incorporated Protein Diodes Show Collective Properties. Nat. Nanotechnol. 2009, 4, 437-440.

(34) Ciaccia, M.; Di Stefano, S. Mechanisms of Imine Exchange Reactions in Organic Solvents. Org. Biomol. Chem. 2015, 13, 646-654.

(35) Banerjee, A.; Mikhailova, E.; Cheley, S.; Gu, L. Q.; Montoya, M.; Nagaoka, Y.; Gouaux, E.; Bayley, H. Molecular Bases of Cyclodextrin Adapter Interactions with Engineered Protein Nanopores. Proc. Natl. Acad. Sci. U. S. A. 2010, 107, 8165-8170.

(36) Blaschke, U. K.; Cotton, G. J.; Muir, T. W. Synthesis of MultiDomain Proteins Using Expressed Protein Ligation: Strategies for Segmental Isotopic Labeling of Internal Regions. Tetrahedron 2000, 56, 9461-9470.

(37) Arnold, U.; Hinderaker, M. P.; Nilsson, B. L.; Huck, B. R.; Gellman, S. H.; Raines, R. T. Protein Prosthesis: A Semisynthetic Enzyme with a Beta-Peptide Reverse Turn. J. Am. Chem. Soc. 2002, $124,8522-8523$.

(38) Kienhofer, A.; Kast, P.; Hilvert, D. Selective Stabilization of the Chorismate Mutase Transition State by a Positively Charged Hydrogen Bond Donor. J. Am. Chem. Soc. 2003, 125, 3206-3207.

(39) Sayer, J. M.; Peskin, M.; Jencks, W. P. Imine-Forming Elimination-Reactions 0.1. General Base and Acid Catalysis and Influence of Nitrogen Substituent on Rates and Equilibria for Carbinolamine Dehydration. J. Am. Chem. Soc. 1973, 95, 4277-4287.

(40) Sayer, J. M.; Pinsky, B.; Schonbrunn, A.; Washtien, W. Mechanism of Carbinolamine Formation. J. Am. Chem. Soc. 1974, 96, 7998-8009.

(41) Suratt, E. C.; Proffitt, J. R.; Lester, C. T. Rate of Oxime Formation of Some Aryl Alkyl Ketones. J. Am. Chem. Soc. 1950, 72, $1561-1561$.

(42) Selvaraj, K.; Nanjappan, P.; Ramalingam, K.; Ramarajan, K. Reactivities of Variously Substituted 4-Heteracyclohexanones in the Formation of Oximes. J. Chem. Soc., Perkin Trans. 2 1983, 49-52.

(43) Movileanu, L.; Bayley, H. Partitioning of a Polymer into a Nanoscopic Protein Pore Obeys a Simple Scaling Law. Proc. Natl. Acad. Sci. U. S. A. 2001, 98, 10137-10141. 